\title{
The Impact of Type of Approach (CLIL Versus EFL) and Methodology (Book-Based Versus Project Work) on Motivation
}

\author{
DAVID LASAGABASTER \\ RAQUEL LÓPEZ BELOQUI \\ University of the Basque Country UPV/EHU
}

Received: 4 March 2013 / Accepted: 8 May 2014

ISNN: $1697-7467$

\begin{abstract}
This study analyses the effect of type of approach and methodology on different types of motivation: intrinsic, extrinsic, instrumental and integrative motivation; interest in other cultures and learning environment are also considered. The two types of approaches under scrutiny are CLIL (Content and Language Integrated Learning) and non-CLIL or EFL (English as a foreign language), and the two types of methodology are based on either the textbook or project work (PW). Previous studies have examined the effect of PW and/or CLIL on secondary education (Seikkula-Leino, 2007, Lasagabaster, 2011; Sierra, 2011), but the novelty of the present research lies in the fact that it is focused on primary education students. The data were collected through a questionnaire filled in by three groups of participants: a non-CLIL and book-based group taught conventionally, a CLIL and book-based methodology group, and a CLIL and PW group. The results bore out that CLIL is beneficial for some motivational clusters even at an early age, whereas the impact of PW was not as positive as expected.
\end{abstract}

Keywords: Motivation, CLIL, project work, primary education.

El efecto del tipo de enfoque (AICLE versus ELE) y de metodología (libro de texto versus trabajo por proyectos) en la motivación

RESUMEN: En este estudio se examina el efecto del tipo de enfoque y de la metodología en diferentes tipos de motivación: intrínseca, extrínseca, motivación instrumental e integradora, al tiempo que también se presta atención al interés en otras culturas y al ambiente de aprendizaje. Los dos tipos de enfoque bajo estudio son AICLE (Aprendizaje Integrado de Contenidos y Lengua Extranjera) y no-AICLE o enseñanza tradicional del inglés como asignatura de lengua, y los dos tipos de metodología se basan o bien en el libro de texto o bien en el trabajo por proyectos. Mientras estudios anteriores han analizado el efecto del TP y/o AICLE en educación secundaria (Seikkula-Leino, 2007, Lasagabaster, 2011; Sierra, 2011), la principal novedad del presente estudio radica en que se centra en estudiantes de educación primaria. El instrumento utilizado fue un cuestionario cumplimentado por tres grupos de participantes: un grupo no-AICLE que aprendía inglés como asignatura basándose en el libro de texto, un grupo AICLE que seguía una metodología centrada en el libro de texto, y un grupo AICLE que trabajaba por proyectos. Los resultados confirman que AICLE afecta positivamente distintos aspectos motivacionales incluso a edades tempranas, mientras que el efecto del TP no resultó tan beneficioso como se esperaba.

Palabras clave: Motivación, AICLE, trabajo por proyectos, educación primaria. 


\section{INTRODUCTION}

Content and Language Integrated Learning (CLIL) has become a highly topical issue due to its substantial increase in popularity, not only in Spain but also in several other European countries (Coyle et al., 2011). Effects of CLIL programs on students' language proficiency have been widely discussed in the literature, however, the effect of CLIL on students' motivational patterns is a fairly new topic which seems to indicate that CLIL programs may have a positive effect on secondary education students' motivation (Lasagabaster, 2011; Seikkula-Leino, 2007). Taking into account that studies have mainly been focused on secondary education or university students, this study seeks to find whether CLIL programs boost students' motivation towards English learning in primary education classes. Thus, the effect of CLIL on different types of motivation such as Intrinsic Motivation, Extrinsic Motivation, Integrative Motivation and Instrumental Motivation, as well as students' Interest in other cultures will be researched.

Furthermore, in the English learning classroom new methodologies such as Project Work (PW) have been implemented. PW is said to increase students' motivation towards the learning process (Stoller, 2002), but little research has been focused on this aspect in the Spanish context (Sierra, 2011), especially at primary education level. This study examines whether PW boosts the motivation of primary school pupils, the importance of motivation and its pedagogical implications for CLIL students and the possible effect that PW may have on their motivation.

\section{Literature ReView}

\subsection{Content and Language Integrated Learning}

Since the mid-nineties, the Council of Europe and the European Commission have been raising awareness and promoting the learning of foreign languages through the education system. In 1995, in the White Paper entitled Teaching and Learning: towards the Learning Society, the European Commission stated that everyone should be able to communicate in two European languages in addition to their mother tongue. The Commission also affirmed that it was desirable to start studying a foreign language at pre-school level. During the same year, European Council resolution highlighted the importance of implementing innovative methods to provide bilingual and intensive teaching. The importance of providing successful language training for teachers and mobility opportunities within the European educative systems was also underscored.

The consequence was that multiple bilingual educational programs and methods were developed during the following years in an attempt to meet the needs of the different contexts in Europe, resulting in a wide variety of initiatives. They were labelled using some of the already existing terminology from Canadian French immersion programs developed during the 1960s. Nevertheless, and due to the idiosyncrasies of the European context, there was a need to adopt a new term to refer to these programs.

The acronym CLIL was coined in the 1990s and was adopted as an umbrella term to define "any dual-focused educational context in which an additional language, thus not 
usually the first language of the learners involved, is used as a medium in the teaching and learning of non-language content" (Marsh, 2002: 15). The reason for its increasing use was that "it placed both language and non-language content in a form of continuum, without implying preference for one or the other" (Marsh, 2002: 58).

Thus, CLIL students are given the opportunity to use another language in different contexts and to develop their intercultural and language skills while learning the curriculum content. Aside from the linguistic and educational objectives, it was considered important to prepare students for life in an internationalized society by providing them with resources for the labor market (socio-economic objective), as well as to instill values of respect and tolerance towards other cultures (socio-cultural objective).

SLA (Second Language Acquisition) research studies provide some arguments in favor of CLIL programs on the grounds that they create conditions for naturalistic language learning, increase the time of exposure to the foreign language and provide an aim for language use in the classroom (Dalton-Puffer \& Smit, 2007).

CLIL's main characteristics or defining principles are described by Coyle (2007) in her $4 \mathrm{Cs}$ conceptual framework. This framework provides the basis for upcoming pedagogies to be developed and pays heed to the relationship between Content, Communication, Cognition, and Culture. The first C, Content, refers to the main objective which is learning the subject matter and acquiring knowledge. The second principle sets language as the means for both learning and communication. Students learn the foreign language by using it in different classroom situations, while developing a wide range of language skills. Cognition refers to the cognitive challenge that CLIL should provide to students when it comes to developing thinking skills, language proficiency and interpersonal communication skills. Finally, the fourth principle brings students closer to other cultures by linking language, thinking, and culture. It helps them develop social awareness of other cultures and their own. This is the reason why CLIL students' interest in other cultures (as part of students' motivation) will be under scrutiny in our study.

\subsection{Motivation}

Motivation is a determining factor regarding effective L2 acquisition and, consequently, it is one of the most widely researched variables in SLA. With a view to addressing this topic, we will first define motivation and tackle its characteristics. Dörnyei (2005: 68) defined motivation as the "effort, desire, and attitude towards learning." In our study different motivational components are going to be examined: Intrinsic motivation, Extrinsic motivation, Instrumental motivation, Integrative motivation, and Interest in other cultures.

Following Ryan and Deci's (2000) Self-Determination Theory, we will make a distinction between intrinsic and extrinsic motivation. In Ryan and Deci's work (p. 55) "Intrinsic motivation is defined as the doing of an activity for its inherent satisfactions rather than for some separable consequence." In other words, students will learn a second language because of the inner rewarding or satisfaction gained in the process. Intrinsic motivation could be motivated by the task they do or the process they have to follow, that is, by the feelings experienced while doing a particular task. In education it usually becomes weaker as children go through school (Chambers, 1999). Intrinsic motivation has been proved to be greater in students whose parents and teachers have supported their autonomy (Grolnick, Deci, \& Ryan, 1997). 
Extrinsic motivation is defined by Ryan and Deci (2000: 55) as "doing something because it leads to a separable outcome". In other words and applied to second language acquisition, students learn a foreign language because of external factors such as parental pressure or the fear of being punished.

In the L2 motivation field, one of the most widely known concepts of Gardner's (1985) theoretical framework is integrative motivation. This concept was defined by Gardner and Lambert (1972: 132) as "reflecting a sincere and personal interest in the people and culture represented by the other group". Languages are learned in order to interact, respect and learn about the second language community. This affect could be shown by learners' identification and openness to elements of the language and the culture of the language itself.

In addition to this, Gardner (2001) proposed that the concept of integrative motivation could be associated with instrumentality, which led to instrumental motivation. He affirmed that "there can be other supports for motivation not directly associated with integrative motivation. Thus, there may be instrumental factors contributing to motivation, and we could label this combination of instrumental factors and motivation as Instrumental Motivation" (Gardner, 2001: 7). Instrumental motivation has also been widely researched and discussed (Dörnyei, 1990; Gardner, 1985). The main driving force in this type of motivation is the usefulness of learning a second language as a means to achieve higher aspirations such as getting a better job. Csizér and Dörnyei (2005) pointed out that this form of motivation might not be influential enough in young learners of the language for whom it is not so relevant. However, Dörnyei (2000) renamed instrumental motivation as incentive motives, which include goals such as understanding foreign friends or English lyrics in songs other than job prospective.

Nowadays English has become the main global lingua franca and the concept of global identity is linked to English language which has led authors such as Kimura, Nakata, and Okumura (2001 in Dörnyei, 2005) to conclude that there is a sharing of integrative and instrumental motives.

Interest in other cultures reflects the motivation learners have to learn a foreign language in order to appreciate other cultures and get closer to L2 communities. The direct contact with the native-speaker culture may be minimal, but thanks to the English classes and the media, students get closer to other cultures beyond that of native speakers.

\subsection{Motivation in CLIL programs}

As stated before, several studies have examined whether CLIL programs have positive effects on students' foreign language proficiency levels (Dalton-Puffer, 2011). As far as motivation is concerned, studies researching this area in language learning have mainly focused on English as a Foreign Language (EFL) programs, whereas CLIL has hardly ever been incorporated in the motivation equation, as a result of research on CLIL being relatively young (Dalton-Puffer, 2011; Seikkula-Leino, 2007). Although CLIL is believed to foster learners' motivation because it increases the level of authenticity and challenge, and because it encourages the learner to view the foreign language as important and meaningful as other subjects in the curriculum (Coyle et al., 2011; Hunt, 2011), there is little research on how CLIL programs affect motivation. In the following lines we will briefly review some of the studies undertaken in the last few years. 
Hunt (2011) reports a study carried out in England and in which learners responded positively to the CLIL lessons, as they enjoyed the lessons, the activities and the resources, while they also felt that they made progress. However, the category which was less positive was the one concerned with their feeling motivated, which the author puts down to the fact that this particular item was misunderstood by the students, as all the remaining responses indicated greater motivation. Seikkula-Leino (2007) examined the effect of CLIL on learners' two affective factors: self-esteem and motivation, the second factor relating it to our research. The study included 217 Finnish students from grades 5 and 6 in a comprehensive school, 116 of whom were on CLIL programs in English, programs in which $40-70 \%$ of the curriculum was taught in the foreign language. Results showed that students enrolled in the CLIL program had lower self-esteem regarding their foreign language capabilities, but higher motivation: "All in all, this study indicates that pupils in CLIL were somewhat more motivated to study and to use a foreign language than pupils learning in Finnish. However, let us note that their enthusiasm was relatively moderate" (Seikkula-Leino, 2007: 338).

In Spain, Lorenzo et al. (2009) undertook one of the few studies in which both primary and secondary education students (for a total of 1,768 participants) were involved. These authors observed that CLIL increased students' motivation both in primary and secondary education, but their results also revealed that the former were more highly motivated than their secondary education counterparts. Lasagabaster (2011) researched the influence of CLIL on motivation. In this case 191 secondary school students enrolled in CLIL programs and EFL classes participated in the research. Motivational results were obtained from a 13item questionnaire based on previous studies. Items were grouped in three factors: interest and instrumental orientation, attitudes towards learning English in class and effort. CLIL students appeared to be more motivated than their EFL counterparts in the three different factors mentioned. Thus, it was concluded that there is an important relationship between motivation and the CLIL approach.

Research so far seem to indicate that secondary school CLIL students are more motivated. This study asks whether the same can be said for primary school pupils, as, to our knowledge, only the previously mentioned studies by Lorenzo et al. (2009) and SeikkulaLeino (2007) have focused on primary education. Nevertheless, it is worth pointing out that none of these two previous studies (Lorenzo et al., 2009; Seikkula-Leino, 2007) delved into the effects of CLIL on different types of motivation -but rather on motivation as a general construct-, as we intend in the present study.

\subsection{Project Work and motivation}

PW has been introduced in Spanish classrooms in the last few decades, but still there is not a definitive answer about the following question: Does it have a positive influence on students' motivation towards language learning? PW is defined as "long-term, problemfocused, and meaningful activities that bring together ideas and principles from different subject areas or disciplines" (Goodrich et al., 1995: viii). Its methodology is student-centered and boosts cooperativeness between students in order to develop a final task or project integrating all their skills. PW has been experimented with, but "it is far from generalized, and the results of many of these endeavours remain unpublished", despite the fact that PW can also "play a leading role in promoting meaningful student engagement with language and content learning" (Sierra, 2001: 211-212), which makes it very suitable for a CLIL context. 
Project work is said to be motivating, stimulating and challenging (Stoller, 2002), but Ribé (2000: 63) affirms that it "also requires from the student not only a considerable workload, but also a high degree of personal commitment". Students whose motivational orientation focuses on learning the subject matter will show a higher engagement with PW than those whose orientation will be to perform well or just complete the assigned work (Thomas, 2000). In other words, those students who have stronger intrinsic motivation rather than extrinsic will be more motivated and more engaged in PW.

In order to implement PW in the classroom teachers and students should follow several steps that characterize the process. Firstly, they will have to agree on the main topic of the project (e.g. insects) and on the final task they are going to present (e.g. a written report, a debate, an oral presentation, or a final poster). Secondly, the students and the instructor design the structure of the project. They will decide on the procedure to get to the final task. First it will be to gather the necessary information. In order to do so, the teacher will prepare the students for the language demands that the information gathering process will have, as well as for the demands that the data compilation and the analysis of the information process will require. Once the data has been compiled and the information analyzed, the teacher will prepare the students with the necessary vocabulary and language demands to overcome the final task. Finally, the students will present the final activity and it will be evaluated (Stoller, 2002).

Several research projects have been carried regarding the PW approach. However, those that have researched its effect on student motivation are scant. Some studies referring to this topic have been undertaken in Singapore. Liu et al. (2009) tested 767 students whose motivational patterns were divided into four different clusters. Students who showed "highest scores in intrinsic and identified regulations and extremely low scores in external regulation and amotivation" (2009: 141), called high self-determination / low controlled cluster, appeared to be the most motivated ones, and those with "low introjected and external regulations" (2009: 141) in the low self determined / high controlled group the least. The first group perceived PW as a more motivating learning experience than the rest. The authors stated that "students' motivational regulations and their perceived needs satisfaction at the start of PW is related to their experience of and learning in PW" (Liu et al., 2009: 144).

Koh et al. (2009) researched students' motivation through Self-Determination Theory and concluded that students involved in PW were more extrinsically motivated. The authors considered that in order to improve intrinsic motivation as well, PW organizers should stimulate problem solving and communication. In the USA, several studies have focused on PW outcomes, increased motivation being one such outcome. Through classroom observation and teacher interviews, the Expeditionary Learning schools were reported to improve school climate and boost student motivation (Thomas, 2000). Bartscher, Gould, and Nutter (1995, in Thomas, 2000) reported that $82 \%$ of students who were previously identified as having low motivation, after taking part in PW, reported that the methodology followed had motivated them. In addition to this, 93\% admitted an increased interest in the topics involved.

In Spain, few research projects have analyzed the effect of PW on motivation. Research carried out by Ribé (2000) followed the progress of 40 sixteen-year-old secondary school students from Barcelona who worked on projects for nine weeks. Results and students' diaries 
demonstrated that over $80 \%$ of the students showed a high degree of acceptance towards the methodology followed during the process. They also said they had learned plenty of English, while "the sense of achievement was high" (Ribé, 2000: 78). The study undertaken by Sierra (2011) included fifty-nine first year secondary education students. These students developed three music projects in English during the 2008/2009 school year, and then filled out an individual 29-item questionnaire. Results showed that there was a high motivation pattern among the students, and a high level of satisfaction from working cooperatively, personal work and content and language learning. In addition to this, they had a good impression of CLIL, $86.5 \%$ of them rating it as very good or good in the questionnaire.

These studies seem thus to confirm the positive impact of PW on students' motivation, at least in secondary schools, as the results obtained in the research studies reviewed above indicate that students enjoy PW, feel motivated and manifest a high level of satisfaction during its implementation (Sierra, 2011). Let us look next at whether such positive outcomes would be replicated at primary school level.

\section{RESEARCH QUESTIONS}

Bearing in mind the above review of the literature, this study puts forward the following two research questions:

(1) Are primary-education CLIL pupils more motivated to learn English than their EFL counterparts?

(2) Are pupils who do project work as part of a CLIL program more motivated towards language learning than those who do not?

In accordance with results obtained in secondary education (Seikkula-Leino, 2007; Lasagabaster, 2011), it is expected that schoolchildren attending CLIL programs will be more motivated towards foreign language learning than those enrolled in EFL. We hypothesize that the CLIL program will have positive effects on the different types of motivation, although students will not be equally motivated for each of them. Since the participants are young primary education pupils, intrinsic motivation levels are expected to be higher than the extrinsic ones, whereas instrumental motivation is expected not to be "directly relevant" for students at this early age (Csizér and Dörnyei, 2005). Regarding integrative motivation, as English is a foreign language and it is not present in students' everyday lives outside school, integrative values are not expected to be very high (Lamb, 2004). Finally, we assume that Interest in other cultures will follow a similar trend to that of integrative motivation.

Based on results obtained in secondary education (Liu et al., 2009; Koh et al., 2009; Thomas, 2000; Ribé, 2000; and Sierra, 2011), in our second research question we expect that primary-school children doing project work will also show more motivation than those students enrolled in classes that relied heavily on the textbook. 


\section{Method}

\subsection{Participants}

The study involved a total of 87 primary education students who were enrolled in the $5^{\text {th }}$ grade of primary education (10-11 year olds) in three different public schools in Navarre, one of the 17 autonomous communities that make up Spain. In this context the presence of English out of formal teaching contexts is minimal.

The schools where the research took place belong to the public education system and are located in different neighborhoods in Pamplona, with the socio-economic and socio-cultural context being similar in all three. The schools were selected taking into account different characteristics connected with the research study, such as CLIL or PW implementation. In addition to this, we selected two of them because they had the longest running CLIL programs in Navarre. Their main characteristics were the following:

School A: 32 students, divided into 14 boys and 18 girls. These had five hours of traditional EFL classes per week and had been studying English since kindergarten (that is, for 7 years). The English classes were based on "The incredible English Kit 5" textbook.

School B: 23 students, 10 boys and 13 girls. The school has been taking part in the CLIL program promoted by the Spanish Ministry of Education and the British Council since the 2007/2008 school year. Thus, the students had been following the CLIL curriculum since they started primary education, which means that they had been participating in the program for five years when the study was carried out. Teachers followed the handbook "Orientaciones para el desarrollo del currículo integrado hispano-británico en educación primaria" (Guidance for integrated Hispanic-British curriculum development in primary education) when teaching. Students attended art and physical education in English, whereas maths and science were taught in both languages: 50\% in English and 50\% in Spanish. In total, pupils had 12 hours of CLIL per week in English. In this school all students also attended conventional EFL classes. The teachers working in this school based their classes on textbooks, the science teachers being the only exception. Since both the Spanish and English science teachers shared the subject and the same groups of students, they created their own materials and working sheets that replaced the textbook. In this school PW was not part of the teaching methodology.

School C: 32 students, 15 boys and17 girls. Like school B above, a CLIL program sanctioned by the Spanish Ministry of Education and the British Council, following the same handbook. Our sample had been following the CLIL curriculum for five years, since starting primary education. They attended physical education and computers in English, and maths and science were taught in both languages (50\% in English and 50\% in Spanish), a total of 12 hours per week in English. The methodology employed in all classes was PW. When the survey was conducted they were working on insects. This group also had conventional EFL classes. In this school all the school subjects were PW-based. Students implemented a different project every term and, at the time of the questionnaire administration, they were in the initial phase of the PW on insects. Typically, the teacher would help them to fill out a chart which consisted of three sections: what we know, what we want to know, and what we learnt. The pupils were given enough freedom to implement the project and link it to 
their interests, although the teacher would always lead their work and make the necessary connections to the curriculum contents.

Table 1: Characteristics of the participants in each school.

\begin{tabular}{|c|c|c|c|c|c|}
\hline & Students & Gender & Approach & $\begin{array}{c}\text { Exposure to } \\
\text { English }\end{array}$ & Methodology \\
\hline School A & 32 & $\begin{array}{c}43.7 \% \mathrm{M} \\
56.2 \% \mathrm{~F}\end{array}$ & Non-CLIL & $\begin{array}{c}5 \text { hours per } \\
\text { week } \\
\text { (EFL) }\end{array}$ & Traditional \\
\hline School B & 23 & $\begin{array}{c}43.4 \% \mathrm{M} \\
56.5 \% \mathrm{~F}\end{array}$ & CLIL & $\begin{array}{c}12 \text { hours per } \\
\text { week } \\
\text { (EFL + CLIL) }\end{array}$ & Book-based \\
\hline School C & 32 & $\begin{array}{c}46.8 \% \mathrm{M} \\
53.1 \% \mathrm{~F}\end{array}$ & CLIL & $\begin{array}{c}12 \text { hours per } \\
\text { week } \\
\text { (EFL + CLIL) }\end{array}$ & PW \\
\hline
\end{tabular}

\subsection{Instrument}

A motivation questionnaire based on previous studies in the area (Pintrich et al., 1991; Kurzel and Rath, 2007) was designed. Items were translated into Spanish so that learners would not struggle with language difficulties. The questionnaire was piloted on a dozen students from another public school in Pamplona, because, although we adopted items from existing instruments that had been through extensive piloting, it still needed to be piloted for the specific population that we intend to use it for.

The questionnaire consisted of 48 items presented on a five-point Likert scale ranging from 1 (strongly disagree) to 5 (strongly agree). Statements were made referring to the five dimensions of motivation we aimed to research into and Alpha Cronbach tests were performed to check the reliability of the scales. The results and the items included in each of the scales are shown in table 2, and the Alpha Cronbach value for the entire set of statements was 0.804 . The statistical analysis showed good alpha ratings for the five dimensions, as they were all above 0.60 . Moreover, we looked at the alpha statistics to check if the deletion of any particular item would add to the internal consistency of the different scales. The statistical analysis revealed that one of the items included in the Interest in other cultures dimension should be eliminated, as its elimination made the alpha rating rise from 0.565 to 0.850 . 
Table. 2. Alpha Cronbach reliability tests.

\author{
Intrinsic motivation \\ $\alpha=0.827$ (10 items) \\ Extrinsic motivation \\ $\alpha=0.656$ (6 items) \\ Instrumental motivation \\ $\alpha=0.791$ (7 items) \\ Integrative motivation \\ $\alpha=0.647$ (5 items) \\ Interest in other cultures \\ $\alpha=0.857$ ( 2 items)
}

In addition to this, it also included a final section called Learning Environment made up of 18 items. This was aimed at answering the second research question of the study. The items included in this cluster were focused on whether pupils preferred working individually, whether they found class activities interesting, whether class materials were boring or were related to their interests and real life.

\title{
4.3. Procedure
}

The same procedure was followed in the three schools participating in the study. We approached them by sending a letter that provided information about the aim of the study and how the questionnaires would be administered, together with a sample questionnaire.

After having obtained consent from the three schools to carry out the study, we guaranteed confidentiality to the students. Accordingly, the questionnaires were completed during certain lessons in the students' own classrooms. One of the researchers presented the questionnaire and provided an explanation in Spanish. It was highlighted, for students to be completely sincere, that the results were not going to have any academic consequence and that the teacher would not see their responses. Students took 30 minutes on average to answer it.

\section{Results}

\subsection{Motivation in EFL and CLIL groups}

In order to answer the first research question, we compared the questionnaire results in each of the first five clusters mentioned above from students attending an EFL program in School A and students attending a CLIL program in School B, both following a book-based 
methodology in the classroom. Results revealed that CLIL has a positive influence on some of the different motivation clusters. Results are summarized in Table 3. One-way ANOVA analyses were performed between each of the clusters and the school setting.

Table 3: Motivation in EFL and CLIL groups. ${ }^{*} p<0.01 ; * * p<.001$.

\begin{tabular}{|c|c|c|c|c|}
\hline Motivation Cluster & Model & Mean & SD & $\mathbf{F}$ \\
\hline Intrinsic motivation & $\begin{array}{c}\text { EFL } \\
\text { CLIL }\end{array}$ & $\begin{array}{l}4.31 \\
4.77\end{array}$ & $\begin{array}{l}0.40 \\
0.21\end{array}$ & $25.14 * *$ \\
\hline Extrinsic motivation & $\begin{array}{c}\text { EFL } \\
\text { CLIL }\end{array}$ & $\begin{array}{l}2.74 \\
2.64\end{array}$ & $\begin{array}{l}0.82 \\
0.59\end{array}$ & 0.21 \\
\hline Instrumental motivation & $\begin{array}{c}\text { EFL } \\
\text { CLIL }\end{array}$ & $\begin{array}{l}3.20 \\
3.58\end{array}$ & $\begin{array}{l}0.77 \\
0.88\end{array}$ & 2.91 \\
\hline Integrative motivation & $\begin{array}{c}\text { EFL } \\
\text { CLIL }\end{array}$ & $\begin{array}{l}2.87 \\
3.47\end{array}$ & $\begin{array}{l}0.89 \\
0.65\end{array}$ & $7.66^{*}$ \\
\hline Interest in other cultures & $\begin{array}{c}\text { EFL } \\
\text { CLIL }\end{array}$ & $\begin{array}{l}3.85 \\
3.78\end{array}$ & $\begin{array}{l}0.94 \\
1.41\end{array}$ & 0.24 \\
\hline
\end{tabular}

Differences between the means of the items comprised in the Intrinsic motivation cluster from students in school A and school B were compared and the results were statistically significant. Results from school A (EFL) presented a mean of 4.31, whereas students enrolled in CLIL in school B were more motivated (mean=4.77). It has to be pointed out that the means for the items comprised in this cluster were very high for both groups (clearly the highest in all clusters), but this was especially so in the case of the CLIL group. Differences were also observed in Integrative motivation. Students attending the CLIL program (3.47) presented a higher mean than the EFL pupils (2.87) in the items related to this specific cluster, and in this case the difference also turned out statistically significant $(\mathrm{p}<0.01)$.

Although students in school A seemed to be more extrinsically motivated than those in school B (the mean score being 2.74 for the EFL group and 2.64 for the CLIL group), the difference was not statistically significant $(\mathrm{p}=.647)$. It has to be underscored that the means for Extrinsic motivation were much lower than those for Intrinsic motivation. Instrumental motivation was higher among CLIL students (3.58) than among their EFL counterparts (3.20), but once again the difference between the means was not statistically significant $(\mathrm{p}=0.094)$. Regarding the Interest in other cultures cluster, no significant differences were observed between the means of school A (3.63) and school B (3.65).

Out of all the battery, both groups of students coincided by valuing the same three items the most (Table 4). Negative item 21 ("Learning English is useless") was the most valued. Once reversed, it presented a mean of 4.94 for the EFL group and 5.00 (the maxi- 
mum) for the CLIL group. Another negative item, namely item 9 ("Learning English is a waste of time"), came second with means of 4.80 and 5.00 respectively. Thirdly, item 2 ("I learn English because it is an important school subject") presented the third highest mean, 4.70 in the case of the EFL students and 4.91 for the CLIL group. In spite of Integrative motivation being the most valued cluster, the highest rated item belonged to the Instrumental motivation cluster. Nevertheless, the second and third most valued items were from the Integrative motivation cluster and, as mentioned above, this was the cluster with the highest mean score by far. It is worth pointing out that these three items dealt with the idea of English being an important subject to master.

Table 4: The most valued items in the questionnaire.

\begin{tabular}{|c|c|c|l|c|c|l|}
\hline & \multicolumn{3}{|c|}{ EFL } & \multicolumn{3}{c|}{ CLIL } \\
\cline { 2 - 7 } & Item & Mean & Cluster & Item & Mean & \multicolumn{1}{c|}{ Cluster } \\
\hline $1^{\text {st }}$ & 21 & 4.94 & Instrumental Mot. & 21 & 5.00 & Instrumental Mot. \\
\hline $2^{\text {nd }}$ & 9 & 4.80 & Intrinsic Mot. & 9 & 5.00 & Intrinsic Mot. \\
\hline $3^{\text {rd }}$ & 2 & 4.70 & Intrinsic Mot. & 2 & 4.91 & Intrinsic Mot. \\
\hline
\end{tabular}

\subsection{Motivation, PW and the book-based methodology}

In order to answer the second research question we will take into account the quantitative items answered by the students attending schools B and C. We will firstly look at the influence of the methodology implemented in the classroom on the different motivational clusters, including now the Learning environment. Table 5 summarizes the results of these different clusters.

Table 5: Motivation in PW and non PW groups. * $p<0.05$; ** $p<0.01$.

\begin{tabular}{|c|c|c|c|c|}
\hline Motivation Cluster & $\begin{array}{l}\text { Methodology } \\
\text { (CLIL groups) }\end{array}$ & Mean & SD & $\mathbf{F}$ \\
\hline Intrinsic Motivation & $\begin{array}{c}\text { Book-based (B) } \\
\text { PW (C) }\end{array}$ & $\begin{array}{l}4.77 \\
4.34\end{array}$ & $\begin{array}{l}0.21 \\
0.67\end{array}$ & $8.72 * *$ \\
\hline Extrinsic Motivation & $\begin{array}{c}\text { Book-based (B) } \\
\text { PW (C) }\end{array}$ & $\begin{array}{l}2.64 \\
2.61\end{array}$ & $\begin{array}{l}0.59 \\
0.94\end{array}$ & 0.02 \\
\hline Instrumental Motivation & $\begin{array}{c}\text { Book-based (B) } \\
\text { PW (C) }\end{array}$ & $\begin{array}{l}3.58 \\
2.29\end{array}$ & $\begin{array}{l}0.88 \\
0.75\end{array}$ & 1.85 \\
\hline Integrative Motivation & $\begin{array}{c}\text { Book-based (B) } \\
\text { PW (C) }\end{array}$ & $\begin{array}{l}3.47 \\
3.03 \\
\end{array}$ & $\begin{array}{l}0.65 \\
0.64 \\
\end{array}$ & $6.10^{*}$ \\
\hline Interest in other cultures & $\begin{array}{c}\text { Book-based (B) } \\
\text { PW (C) }\end{array}$ & $\begin{array}{l}3.78 \\
4.03\end{array}$ & $\begin{array}{l}1.41 \\
0.96\end{array}$ & 0.77 \\
\hline Learning Environment & $\begin{array}{c}\text { Book-based (B) } \\
\text { PW (C) }\end{array}$ & $\begin{array}{l}3.46 \\
3.88\end{array}$ & $\begin{array}{l}0.52 \\
0.51\end{array}$ & 0.31 \\
\hline
\end{tabular}


The differences in the Intrinsic motivation cluster turned out to be statistically significant $(p=0.005)$. In fact, students who followed a more conventional methodology (mainly based on a textbook) rated this cluster higher than those implementing activities through PW: 4.77 in the case of school B (book-based methodology) and 4.34 of school C (PW methodology).

Regarding Integrative motivation, students from school B were more motivated (3.47) than those from school C (3.03). In this case the difference also happened to be statistically significant $(\mathrm{p}=0.017)$. In this case the trend is the same as that for intrinsic motivation, as students from school B, which is not implementing PW but rather following a more traditional methodology based on the textbook, rated this cluster higher than the students from school C.

No significant differences were observed in the case of the extrinsic motivation, instrumental motivation, and interest in other cultures clusters. In addition to the already described categories, the cluster learning environment was specifically designed to delve into students' opinion about the methodology employed in the classroom and it showed once again no statistically significant differences $(\mathrm{p}=0.63)$.

\section{Discussion}

The results of the study only support part of the first hypothesis. The CLIL type of approach has a positive effect on some components of motivation, as the means of CLIL students were only higher than those of their EFL counterparts in the intrinsic and integrative motivation clusters.

Intrinsic Motivation presented the highest mean of all clusters. As we hypothesized, young learners from primary education maintained greater intrinsic motivation than extrinsic towards language learning. Although both groups presented high means in this cluster, the CLIL students' mean significantly exceeded that of the EFL learners, which seems to indicate that CLIL helps to bolster students' inherent satisfaction while doing their class activities. Thus, students enjoy the inner rewarding (Ryan and Deci, 2000) gained during their CLIL classes and this would help to explain the positive effects of CLIL programs on students' foreign language proficiency (Dalton-Puffer, 2011). Conquering challenges is an important part of intrinsic motivation, and the use of a foreign language as a means to learn content seems to trigger the pleasure that an activity produces in itself.

Similarly, results seem to indicate that CLIL had a very positive effect when it came to increasing young students' integrative motivation, that is, students' interest in interacting and learning about the L2 community of speakers. However, as Ryan and Deci (2000) point out, intrinsic motivation decreases when students go up in the educational ladder. It would be interesting then to develop a longitudinal study to check out whether these positive CLIL effects are maintained in time as students get older and go through secondary education.

Students proved to show very low extrinsic motivation, as predicted. These results showed that EFL pupils were slightly, but not significantly, more extrinsically motivated than students in the CLIL program. Ryan and Deci (2000) affirm that when intrinsic motivation is high, extrinsic motivation tends to be low, and when the latter increases the former decreases. These results lead us to conclude that both EFL and CLIL students' motivation is not determined by external factors such as the need to obey the teacher or their being 
afraid of punishment, but once again this may be the result of our participants being enrolled in primary education, as this trend may change as they progress in the educational ladder. However, it is worth mentioning that the most valued item in the extrinsic motivation cluster showed that parents' opinion influences them, as they considered learning English important because their parents did so. When interpreting this we should consider that parents' opinion is very important for such young learners, as Gardner already pointed out in his seminal work in 1985.

Taking into account Instrumental motivation values on the questionnaire, we should point out that, even though students considered English as useful and important, the mean was not particularly high. The fact that students are not instrumentally motivated could be due (one again) to their being too young to be concerned or aware of the career advantages that foreign language proficiency can bring, which confirms that this type of motivation is not directly relevant for young students (Csizér and Dörnyei, 2005).

CLIL programs seemed to have a clear positive impact on students' integrative motivation, the means of items rated in this cluster by CLIL students being significantly higher than those of the EFL students. Nevertheless, integrative motivation in young learners was not high. English culture does not have a clear presence in this context and there is no meaningful English speaking community in their surroundings. Therefore, they do not regard this cluster as highly as others. Students felt that English was important in order to communicate with people from all over the world and with peers during classes in English. English is the common language used in the CLIL classroom and students deemed it important to be fluent so as to share ideas and work with it.

Strikingly, and even though the CLIL students were enrolled in the MEC-British Council program which includes aspects and concepts dealing with British culture, they were still more interested in American culture. A possible reason for this could be the effect that America as a world power has on society, or the significant impact that movies and TV series have on such young students.

In the Interest in other cultures cluster we discovered that both EFL and CLIL students were similarly motivated, thus, CLIL programs did not have a specific effect on this motivational aspect, as proposed in Coyle's 4Cs conceptual framework (2007). It seems that in primary education, the purported intercultural benefits attached to CLIL are not taken advantage of by teachers, although this is an issue which deserves further research. Many of the supposed benefits of CLIL only have a theoretical basis and there is a need to undertake studies at different educational stages to test if they match what really takes place in the classroom.

Even though the differences were not statistically significant in all the clusters, there seems to be some positive effect of CLIL on student motivation. These results support what Seikkula-Leino (2007) and Lasagabaster (2011) observed among secondary education students, but once again we would like to highlight the importance of longitudinal studies that would help to shed light on the long-term effect of the CLIL approach. Since a consistent pattern regarding the changes of foreign language learners' attitudes over time is that of a general decline (Chambers, 1999), it would be worth analysing the purported positive effect of CLIL over time.

As for the effect of the methodology (book-based versus PW), the results of the two CLIL groups showed that PW does not seem to improve student motivation when com- 
pared with a more traditional approach at this particular age. Intrinsic motivation means were again the highest of all clusters, but the results did not quite meet our expectations, as the students who attended the school whose teaching was based on the book were more intrinsically motivated than those who worked on projects. The same happened in the case of integrative motivation.

The difference in the case of the Extrinsic motivation and the Instrumental clusters were not significant. In the case of the Interest in other cultures, the students attending school C (PW) had higher means than those attending school B, even though the difference between means was not statistically significant. The reason for these results may lie in the fact that $\mathrm{PW}$, as implemented in the school under analysis, did not include topics about other cultures.

Finally, the means of the Learning environment cluster were only slightly different between the two groups and no statistical difference was found. A possible explanation could be that motivation is greater and more generalized among students in primary education and this fact may help to water down the positive motivational stance observed in secondary education among those groups that follow a PW methodology in CLIL settings (Sierra, 2011).

\section{Final CONSIDERATIONS AND PEDAgOgical IMPLications}

The findings of this study show that CLIL has a positive effect on some components of young learners' motivation. The results give evidence of its influence on Intrinsic and Integrative motivation, but not on the other motivational clusters. Contrary to our expectations, PW does not seem to exert any significant positive influence on primary education CLIL learners. However, and due to the role of English as an international language, teachers should aim to focus on integrative motivation geared towards the global community rather than the assimilation with native speakers of English (Lamb, 2004). This study identified an unexpectedly prominent integrative effect of CLIL, probably because the items in the questionnaire made reference to both the British and American community, as well as to the global community. Future studies should include qualitative data to help explore this question.

This study had some limitations as CLIL programs in Navarre are still in their early stages in the different schools, where it is only being implemented in the lower grades. Thus, it would be interesting to do a follow-up study in some years' time, and take into account results from a higher number of schools and a larger sample. In addition to this, the results reveal that CLIL has a very positive effect on students' intrinsic motivation. It would be interesting to do a follow-up study and determine whether this influence continues as students advance in the educational ladder, or whether extrinsic motivation eventually takes over. In this paper we have repeatedly underlined the dire need to gather longitudinal data.

This study has pedagogical implications for schools implementing CLIL programs and PW methodology. Taking into account the prevailing need to learn foreign languages in addition to the mother tongue(s), CLIL may become an effective way to engage students in language learning. In addition to this, PW needs to keep children absorbed and teachers should highlight the projects' connections with real life. Teachers should work on how to design projects that will motivate students more, as merely implementing $\mathrm{PW}$ is not a panacea. The tasks to be carried out in class seem to have a great bearing on student motivation 
and a possible way to arouse more positive feelings could be by negotiating with students about the project to be carried out. This would foster student autonomy and help to bolster their intrinsic motivation. This negotiation process seems worth considering when it comes to further research in the relationship between CLIL and PW.

\section{ACKNowledgements}

The results presented in this paper are part of the following research projects: FFI201234214 (Spanish Ministry of Economy and Competitiveness) and IT311-10 (Basque Government).

\section{REFERENCES}

European Commission (1995). White Paper: Teaching and Learning Towards the Learning Society, Objective IV. Brussels: Council of Europe, DGV.

Chambers, G. N. (1999). Motivating Language Learners. Clevedon: Multilingual Matters.

Coyle, D. (2007). "Content and language integrated learning: towards a connected research agenda for CLIL pedagogies", in The International Journal of Bilingual Education and Bilingualism, 10: 543-562.

Coyle, D., Marsh, D. and Hood, P. (2011). CLIL: Content and Language Integrated Learning. Cambridge: Cambridge University Press.

Csizér, K. and Dörnyei, Z. (2005). "The internal structure of language learning motivation and its relationship with language choice and learning effort", in The Modern Language Journal, 89: 19-36.

Dalton-Puffer, C. (2011). "Content-and-language integrated learning: From practice to principles?", Annual Review of Applied Linguistics 31: 182-204.

Dalton-Puffer, C. and Smit, U. (eds.), (2007). Empirical Perspectives on CLIL Classroom Discourse. Frankfurt: Peter Lang.

Dörnyei, Z. (1990). "Conceptualizing motivation in foreign language learning", in Language Learning, 40: 46- 78 .

Dörnyei, Z. (2000). "Motivation in action: Toward a process-oriented conceptualization of student motivation", in British Journal of Educational Psychology, 70: 519-538.

Dörnyei, Z. (2005). The Psychology of the Language Learner: Individual Differences in Second Language Acquisition. Mahwah, NJ: Lawrence Erlbaum.

Gardner, R. C. (1985). Social psychology and second language learning: The role of attitudes and motivation. London: Edward Arnold.

Gardner, R. C. (2001). "Integrative motivation and second language acquisition", in Z. Dörnyei \& R. Schmidt (Eds.), Motivation and second language learning. Honolulu, HI: University of Hawai'i Press, 1-20.

Gardner, R. C., and Lambert, W. E. (1972). Attitudes and motivation in second language learning. Rowley, MA: Newbury House.

Goodrich, H., Hatch, T., Wiatrowski, G., and Unger, C. (1995). Teaching through projects: Creating effective learning environments. CA: Innovative Learning Publications. 
Grolnick, W. S., Deci, E. L., and Ryan, R. M. (1997). "Internalization within the family: The selfdetermination perspective", in J. E. Grusec \& L. Kuczynski (eds.), Parenting and children's internalization of values: A handbook of contemporary theory. New York: Wiley, 135-161.

Hunt, M. J. (2011). "Learners' perceptions of their experiences of learning subject content through a foreign language", Educational Review, 63: 365-378.

Koh, C., Wang, C. K. J., Tan, O. S., Liu, W. C., and Ee, J. (2009). "Students' discourse and motivation in project work", in P. L. Jeffery (Ed.), Proceedings from the Australian Association for Research in Education International Education Research Conference 2008. Brisbane, Australia: AARE.

Kurzel, F and Rath, M. (2007). "Project Based Learning and Learning Environment", in Journal of Issues in Informing Science and Information Technology (IISIT), 4: 503-510.

Lamb, M. (2004) "Integrative motivation in a globalizing world", in System, 32: 3-19.

Lasagabaster, D. (2011). "English achievement and student motivation in CLIL and EFL settings", in Innovation in Language Learning and Teaching, 5: 3-18.

Liu, w. C., Wang, C. K. J., Tan, O. S., Koh, C. and Ee, J. (2009). "A self-determination approach to understanding students' motivation in project work", in Learning and Individual Differences, 19: 139-145.

Lorenzo, F., Casal, S, Moore, P., Afonso, T. (2009). Bilingüismo y educación. Situación de la Red de Centros bilingües en Andalucía. Sevilla: Centro de estudios Andaluces. Consejería de la Presidencia, Junta de Andalucía.

Marsh, D. (ed.) (2002). CLIL/EMILE-The European Dimension: Actions, Trends and Foresight Potential, Public Services Contract DG EAC, European Commission, Strasbourg.

Muñoz, C. and Navés, T. (2007). "Windows on CLIL in Spain", in A. Maljers, D. Marsh, and D. Wolff (eds.), Windows on CLIL European Centre for Modern Languages. The Hague, European Centre for Modern Languages, 160-165.

Pintrich, P.R., Smith, D.A., García, T. y Mckeachie, W.J. (1991). A manual for the use of the motivational strategies for learning questionnaire (MSLQ). AnnArbor, MI: University of Michigan.

Ribé, R. (2000). "Introducing Negotiation Processes: an Experiment with Creative Project Work", in Breen, M. P. and Littlejohn, A. (Eds). Classroom Decision-Making. Negotiation and Process Syllabuses in Practice. Cambridge: Cambridge University Press, 63-82.

Ryan R.M., Deci E.L. (2000). "Intrinsic and Extrinsic Motivations: Classic Definitions and New Directions", in Contemporary Educational Psychology, 25: 54-67.

Seikkula-Leino, J. 2007. "CLIL learning: Achievement levels and affective factors", in Language and Education 21: 328-341.

Sierra, J.M. (2011). "CLIL and Project Work: Contributions from the Classroom", in Ruiz de Zarobe, Y., Sierra, J.M., and Gallardo del Puerto, F. (eds.) Content and Foreign Language Integrated Learning. Bern: Peter Lang, 211-240.

Stoller, F. (2002). "Project Work: A Means to Promote Language and Content", in Jack, C. Richards \& Willy, A. Renandya (eds.), Methodology in Language Teaching: an anthology of Current Practice. Cambridge: Cambridge University Press, 107-120.

Thomas, J.W., (2000). A Review of Research on Project-Based Learning. San Rafael, CA: Autodesk Foundation. 